\title{
Literature Review: Elective Surgery Guidelines During COVID-19 Pandemic: A Current Literature Review
}

\author{
Hashem Shemshadi $^{* *}$ (D) Fereydoon Layeghi ${ }^{1}$ (D) , Bijan Khorasani ${ }^{1}$ (D) \\ 1. Department of Clinical Sciences, University of Social Welfare and Rehabilitation Sciences, Tehran, Iran.
}

\begin{tabular}{l|l}
\hline $\begin{array}{l}\text { Use your device to scan } \\
\text { and read the article online }\end{array}$ \\
Literature Review. Health in Emergencies and Disasters Quarterly. 2021; 6(2):67-72. http://dx.doi.org/10.32598/hdq.6.2.60.1 \\
dol: $:$ http://dx.doi.org/10.32598/hdq.6.2.60.1
\end{tabular}

\section{(i) $\$$}

Article info:

Received: 29 Apr 2020

Accepted: 02 Dec 2020

Available Online: 01 Jan 2021

\section{Keywords:}

COVID-19, Elective surgery,

Guidelines, Pandemic, Disaster

\section{ABSTRACT}

Background: The primary purpose of this literature review is to investigate different views of elective surgery management during the COVID-19 pandemic. In other words, the guidelines about diseases prevention and their proper management during performing elective surgeries have been reviewed.

Materials and Methods: Current articles related to COVID-19 and practicing elective surgeries in different remarkable EndNote X8 database journals in 2020 were retrieved. All articles referring to COVID-19 precaution rules in implementing elective surgeries were integrated into the article's main goals.

Results: All reviews showed alarming guideline steps that should be taken for validated preventing and managing elective surgeries practiced during the COVID-19 pandemic. Emphasizing qualified elective surgery protocols were quoted in many articles to do elective surgeries with successful results.

Conclusion: Taking effective and evidence-based steps in patients`selection, precautions, and hospitals' safety cares result in protective surgical results. Elective surgeries should be practiced in highly-equipped hospitals with extraordinary quarantine measures during a COVID-19 pandemic. Safety measures are the primary goal for patients, staff, surgeons, and other health providers before surgeons get involved with any elective surgeries during the COVID-19 pandemic. Questions of how different elective surgical operations are planned during the COVID-19 pandemic are essential controversies. As no clear answers are found to questions of how elective surgeries can be practiced during a COVID-19 pandemic, specific rules issued by the world's most authentic surgical associations have been adopted by surgeons to operate elective surgeries.

\section{Introduction}

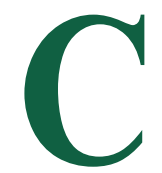

oronavirus disease 2019 (COVID-19) is a viral infection that has adversely changed ecologies, socioeconomics, which have gone beyond expectations. This viral infection has been titled a tragedy or a disaster because of its strange clinical profile, and vigorous spread started from China to most parts of the world [1]. The unique profile of the COVID-19 disease has created serious health hazards

\section{* Corresponding Author:}

Hashem Shemshadi, MD.

Address: Department of Clinical Sciences, University of Social Welfare and Rehabilitation Sciences, Tehran, Iran.

E-mail: shemshadii@gmail.com 
and many deaths around the world. In April 2020, USA CDC (Centers for Disease Control and Prevention) reported that so far, 2.2 million people have been infected, and 0.15 million death occurred globally [2]. An epidemiological study of COVID-19 in Iran, from February 19, 2020, to April 15, 2020, reported 12870 patients referred to different emergency hospitals, 2968 hospitalized patients, and 239 deaths due to the above-mentioned viral infectious disease. In previous studies, the reported patients' ages were in the range of 50-60 years, and the ratio between males to females was 1.9:1 [3]. Most surgery operations have been canceled in the world, except for emergency cases.

At present, elective operations are practicing with caution and reluctance during the COVID-19 pandemic. Due to recent events, surgical preparations and indications for elective surgeries may be resumed with restrictions and strict precautions if the surgeons, staff, and hospitals observe the COVID-19 pandemic's preventive rules [4]. Generally, after taking history and physical examination, most acceptable blood exams associated with COVID-19 viral infection must be obtained from all candidates for elective surgeries. In clinically-suspected cases, chest radiology with computerized chest tomography may be needed to assess patients for their potential contracting with COVID-19. In selecting suitable patients, all cases who are candidates for elective surgery should be nominated seriously. Patients' vital signs, matching with their age, sex, are obtained [5]. Cardiovascular consultations and proper management for patients who want to undergo elective surgery during COVID-19 must be checked carefully [6]. Any elective surgery must be postponed if the appointed patients have any kind of cardiovascular and or other baseline medical issues, and their problems should be solved before implementing their operations [7]. If allocated hospitals are not prepared for potentially susceptible to COVID-19 patients, operations must be terminated and wait for when all required health care is resolved during the COVID-19 pandemic.

Elective surgeries may be delayed till preventive health measures for needy patients are obtained [8]. Patients concerns and hesitations for their probable health misfortunes during elective surgeries must be respected. According to the mentioned reasons, complications may occur throughout their hospitalization. Surgeons should consider their patients' health priorities first and plan an elective surgery on a prepared and well-informed patient about COVID-19 viral infection [9]. Preferred hospitals for performing elective surgeries must be equipped with respiratory care equipment because possible difficulties may occur during patients' hospitalization during the
COVID-19 pandemic. If patients contract COVID-19 and get pneumonia, they require respiratory assists and ventilator apparatuses; otherwise, patients may die [10]. They will die, not because of their original disease but due to fatal respiratory distress due to COVID-19 viral infection [11]. Teamwork, communications, and leadership in executing an elective surgery are highly recommended. Anesthetics should visit preoperatively to review patients' general conditions and act upon their hospitalization toward their isolation from other patients in the surgical wards during the COVID-19 pandemic. Hospitals 'room wards should be separated for each patient, and their related facilities should not be shared [12]

Patients who have undergone a complete examination by anesthetics might reveal many other problems. In selecting patients for undergoing elective surgeries, eliciting their previous anesthesia toxicity, which has not been perceived initially, must be noted and taken under consideration during pandemic COVID-19 [13] Other patients' necessary consultations, in cases suspicious of any types of infections in the past and present times, should be utilized for candidates of elective surgeries [14]. Hospitals where elective surgeries are operated must be equipped with all preventive measures in operating rooms and their hemodialysis departments if any unexpected events occurred $[15,16]$.

The staff should be educated about COVID-19 and be well equipped with a private mask, apron, facial shields, hats, gloves, and covered shoes [17, 18]. Before, during, and after operations, the patients should be under cardiovascular monitoring. Their blood pressures should be checked every four hours until stabilization. Then, they can be followed by routine electrocardiographic monitoring. An expert clinical cardiologist on the site may control the patients' cardiovascular conditions, especially if they are old with other systemic diseases [19]. Patients`screening for having any urogenital problems and their related current treatments are highly important to be reviewed before and after the operation. Underling diseases, such as renal stones, renal-associated high blood pressure, hyperactive bladder, and benign prostate hypertrophy measures, before and after elective surgeries are essential [20]. Ear-nose-throat evaluations, along with proper urologist consultations are benefitting both surgeons and patients $[21,22]$. Post-operative and recovery rooms' strict improvements for possible infections are necessary, especially in high-risk elective operations such as open-heart surgeries [23]. Post-operation rooms for patients recovering from anesthesia should be designed and equipped for COVID-19 viral infection. Such rooms must be equipped with oxygen supplies and 
ventilators for patients awakening from anesthesia and their oxygenation needs. Patients may be protected and follow their safety during this period. Surgical sites may be painful and such pains may be controlled with different sedatives and or other manuals to reduce agonizing discomfort [24]. All elective and emergency operations during COVID-19 must be undertaken entirely. All the staff in recovery rooms must be equipped to protect themselves and patients from contracting COVID-19 viral infections [25]. After patients recovered satisfactorily, post-operative analgesics are given to ensure controlling their surgical sites` discomforts, with permissions of anesthesia groups [26]. Surgical wards located in hospitals must vigorously consider patients' safety and have strong preventive methods of protecting everyone not to be infected with COVID-19 viral infection. Such efforts may be applied in anticipation, management, and proper segregations of resided surgical rooms, and educate staff continuously to follow such protocols till patients get discharged [27]. Hospitalized patients for elective surgeries should have restricted visitors or not at all during their hospital stay. The aforementioned issues must be planned for special days and times of the week in case of the most dangerous respiratory contractions of patients and staff against COVID-19 viral infection [28]. Visitors should be educated to cover their face, body, and hands during such short visit periods and leave the hospital as soon as promising. The previously mentioned prevention protocols are applied to doctors, nurses, and other health providers to assure employing safety measures for all $[29,30]$. Health providers for executing elective surgeries should follow the declared restrictions. Different surgical organizations and societies have alerted their staff, hospitals, and surgeons, to be specifically ready for COVID-19 and its rising fatality issues in the world. Some developing countries, due to their socioeconomic differences with developed countries, have shown fewer efforts in prevention, treatment, and managing the $\mathrm{CO}$ VID-19 pandemic [31]. Most nonemergency operations, such as aesthetic surgeries, may be postponed for more feasible periods [32]. Other types of surgeries, like obstetrics and gynecological surgeries, like ovarian problems, may not be delayed, and their guidelines and surgical precautions during the COVID-19 pandemic have been prepared [33]. In some specialties, residents' training and educational activities are postponed, awaiting for safety periods to come [34].

\section{Materials and Methods}

This literature review was focused on contemporary issues related to observing different validated protocols about executing nonemergency, elective surgeries in the world. Existing articles in related COVID-19 pandemic and practicing elective surgeries in different remarkable EndNote X8 database journals throughout 2020 were retrieved. All articles referring to COVID-19 pandemic precaution rules related to implementing elective surgeries were collected and integrated into this present article.

\section{Results}

Complications related to COVID-19 viral infection are known to all people in the world. Along with the damages imposed by this viral infection, economic situations have been darkened in many countries. Health disasters and their related dilemmas have resulted in economics' turning down in many health care centers in the world. All surgical procedures, and specifically their elective types, have been canceled in many hospitals. In some circumstances, elective surgeries are set aside to be used in other nations. There are some hesitations about starting elective surgeries in some parts of the world, while they are still restricted in other regions. Elective surgeries are governed by authentic surgical associations and may be practiced only with highly restricted guidelines. Those guidelines may benefit some societies, while may not be psychologically, culturally, and economically feasible for other nations. Discrepancies that just mentioned influence the policymakers in different regions of the world, not to follow standard rules and guidelines for allowing elective surgeries to be practiced during the $\mathrm{CO}$ VID-19 pandemic. The raised issues are challengeable and discussible since protecting people under economic pressures may not receive governmental allowances during quarantines related to COVID-19 viral infections.

\section{Discussion}

Validated protocols and guidelines issued by accredited surgical associations in the world should be followed and be implemented during the COVID-19 pandemic. Professional associations usually advise rules which are highly beneficial for disastrous situations like COVID-19. Their protective devices are rated and target hospitals, daycare surgeries, patients, surgeons, and staff who deliver any kind of health care services during this life-threatening era. Prevention rules for not being exposed to COVID-19 infection should be accepted, respected, and enforced by all governmental policymakers during the crisis. Compliance in trends of a variety of diagnostic tools and modern therapeutic modalities must be respected. If elective surgeries can be postponed without causing any psychological and physical damages, they 
must be postponed till the dangerous COVID-19 crisis is slowed down and or vanished in the world forever.

\section{Ethical Considerations}

Compliance with ethical guidelines

This article is a meta-analysis with no human or animal sample, and there were no ethical considerations to be considered in this research.

\section{Funding}

This research did not receive any grant from funding agencies in the public, commercial, or non-profit sectors.

\section{Authors' contributions}

All authors equally contributed to preparing this article.

\section{Conflict of interest}

The authors declared no conflict of interest.

\section{Acknowledgments}

We would link to thank Mallory and Shoeib Shenshadi for their efforts in editing this manuscript's English language.

\section{References}

[1] Ghadimi-Moghadam A, Haghani M, Bevelacqua JJ, Jafarzadeh A, Kaveh-Ahangar A, Mortazavi SM, et al. COVID-19 tragic pandemic: Concerns over unintentional "directed accelerated evolution" of novel Coronavirus (SARS-CoV-2) and introducing a modified treatment method for ARDS. Journal of Biomedical Physics \& Engineering. 2020; 10(2):241-6. [DOI:10.31661/jbpe.v0i0.2003-1085] [PMCID]

[2] Ali I, Alharbi OML. COVID-19: Disease, management, treatment, and social impact. Science of the Total Environment. 2020; 728:138861. [DOI:10.1016/j.scitotenv.2020.138861] [PMID] [PMCID]

[3] Nikpouraghdam M, Jalali Farahani A, Alishiri G, Heydari $\mathrm{S}$, Ebrahimnia M, Samadinia H, et al. Epidemiological characteristics of coronavirus disease 2019 (COVID-19) patients in IRAN: A single center study. Journal of Clinical Virology. 2020 127:104378. [DOI:10.1016/j.jcv.2020.104378] [PMID] [PMCID]

[4] Al-Omar K, Bakkar S, Khasawneh L, Donatini G, Miccoli P. Resuming elective surgery in the time of COVID-19: A safe and comprehensive strategy. Updates in Surgery. 2020; 72(2):291-5. [DOI:10.1007/s13304-020-00822-6] [PMID] [PMCID]
[5] Deeb R. Surgical considerations in patients of middle Eastern descent. Otolaryngologic Clinics of North America. 2020; 53(2):283-98. [DOI:10.1016/j.otc.2019.11.001] [PMID]

[6] Su YB, Kuo MJ, Lin TY, Chien CS, Yang YP, Chou SJ, et al. Cardiovascular manifestation and treatment in COVID-19. Journal of the Chinese Medical Association. 2020; 83(8):704-9. [DOI:10.1097/JCMA.0000000000000352] [PMID] [PMCID]

[7] Kaye K, Paprottka F, Escudero R, Casabona G, Montes J, Fakin R, et al. Elective, non-urgent procedures and aesthetic surgery in the wake of SARS-COVID-19: Considerations regarding safety, feasibility and impact on clinical management. Aesthetic Plastic Surgery. 2020; 44(3):1014-42. [DOI:10.1007/ s00266-020-01752-9] [PMID] [PMCID]

[8] Soreide K, Hallet J, Matthews JB, Schnitzbauer AA, Line PD, Lai PBS, et al. Immediate and long-term impact of the COVID-19 pandemic on delivery of surgical services. British Journal of Surgery. 2020; 107(10):1250-61. [DOI:10.1002/bjs.11670] [PMID] [PMCID]

[9] Bastos LS, Niquini RP, Lana RM, Villela DAM, Cruz OG, Coelho FC, et al. COVID-19 and hospitalizations for SARI in Brazil: A comparison up to the $12^{\text {th }}$ epidemiological week of 2020. Cadernos de Saúde Pública. 2020; 36(4):e00070120. [DOI:10.1590/0102-311×00070120] [PMID]

[10] Papazian L, Klompas M, Luyt CE. Ventilator-associated pneumonia in adults: A narrative review. Intensive Care Medicine. 2020; 46(5):888-906. [DOI:10.1007/s00134-02005980-0] [PMID] [PMCID]

[11] Cinesi Gomez C, Penuelas Rodriguez O, Lujan Torne M, Egea Santaolalla C, Masa Jimenez JF, Garcia Fernandez J, et al. Clinical Consensus Recommendations Regarding NonInvasive Respiratory Support in the Adult Patient with Acute Respiratory Failure Secondary to SARS-CoV-2 infection. Archivos de Bronconeumología. 2020; 56(suppl 2):11-8. [DOI:10.1016/j.redare.2020.05.001] [PMCID]

[12] Firstenberg MS, Libby M, Ochs M, Hanna J, Mangino JE Forrester J. Isolation protocol for a COVID-2019 patient requiring emergent surgical intervention: Case presentation. Patient Safety in Surgery. 2020; 14:15. [DOI:10.1186/s13037020-00243-9] [PMID] [PMCID]

[13] Byram SC, Bialek SE, Husak VA, Balcarcel D, Park J, Dang $\mathrm{J}$, et al. Distinct neurotoxic effects of select local anesthetics on facial nerve injury and recovery. Restorative Neurology and Neuroscience. 2020; 38(2):173-83. [DOI:10.3233/RNN-190987] [PMID] [PMCID]

[14] Allard MA, Blanie A, Brouquet A, Benhamou D. Learning non-technical skills in surgery. Journal of Visceral Surgery. 2020; 157(3 suppl 2):S131-6. [DOI:10.1016/j.jviscsurg.2020.03.001] [PMID]

[15] Abdelrahman T, Beamish AJ, Brown C, Egan RJ, Evans T, Ryan Harper E, et al. Surgery during the COVID-19 pandemic: Operating room suggestions from an international Delphi process. British Journal of Surgery. 2020; 107(11):1450-8. [DOI:10.1002/bjs.11747]

[16] Basile C, Combe C, Pizzarelli F, Covic A, Davenport A, Kanbay M, et al. Recommendations for the prevention, mitigation and containment of the emerging SARS-CoV-2 (COVID-19) pandemic in haemodialysis centres. Nephrology Dialysis Transplantation. 2020; 35(5):737-41. [DOI:10.1093/ ndt/gfaa069] [PMID] [PMCID] 
[17] Mesa Vieira C, Franco OH, Gomez Restrepo C, Abel T. COVID-19: The forgotten priorities of the pandemic. Maturitas. 2020; 136:38-41. [DOI:10.1016/j.maturitas.2020.04.004] [PMID] [PMCID]

[18] Swennen GRJ, Pottel L, Haers PE. Custom-made 3D-printed face masks in case of pandemic crisis situations with a lack of commercially available FFP2/3 masks. International Journal of Oral and Maxillofacial Surgery. 2020; 49(5):673-7. [DOI:10.1016/j.ijom.2020.03.015] [PMID] [PMCID]

[19] Desai R, Singh S, Parekh T, Sachdeva S, Sachdeva R, Kumar G. COVID-19 and diabetes mellitus: A need for prudence in elderly patients from a pooled analysis. Diabetes \& Metabolic Syndrome. 2020; 14(4):683-5. [DOI:10.1016/j. dsx.2020.05.021] [PMID] [PMCID]

[20] Akladios C, Azais H, Ballester M, Bendifallah S, Bolze PA, Bourdel N, et al. Recommendations for the surgical management of gynecological cancers during the COVID-19 pandemic - FRANCOGYN group for the CNGOF. Journal of Gynecology Obstetrics and Human Reproduction. 2020; 49(6):101729. [DOI:10.1016/j.jogoh.2020.101729] [PMID] [PMCID]

[21] Jin B-R, An H-J. Baicalin alleviates benign prostate hyperplasia through androgen-dependent apoptosis. Aging. 2020; 12(3):2142-55. [DOI:10.18632/aging.102731] [PMID] [PMCID]

[22] Kosilov K, Kuzina I, Kuznetsov V, Kosilova L, Ivanovskaya $\mathrm{M}$, Kosilova E. The analysis of the effects of executive functions, working memory and other factors on medication adherence in elderly men with benign prostatic hyperplasia and overactive bladder symptoms. Current Aging Science. 2020; 13(1):72-80. [DOI:10.2174/1874609812666190927153152] [PMID]

[23] Engelman DT, Lother S, George I, Funk DJ, Ailawadi G, Atluri P, et al. Adult cardiac surgery and the COVID-19 pandemic: Aggressive infection mitigation strategies are necessary in the operating room and surgical recovery. The Journal of Thoracic and Cardiovascular Surgery. 2020; 160(2):447-51. [DOI:10.1016/j.jtcvs.2020.04.059] [PMID] [PMCID]

[24] Alican MFB, Ver MR, Ramos MRD, Mamaril LJC. Postoperative single-shot epidural fentanyl and bupivacaine for post-operative analgesia after lumbar decompression: A prospective, double-blind randomized study. Spine. 2020; 45(15):1017-23. [DOI:10.1097/BRS.0000000000003449] [PMID]

[25] De Simone B, Chouillard E, Di Saverio S, Pagani L, Sartelli M, Biffl WL, et al. Emergency surgery during the COVID-19 pandemic: What you need to know for practice. Annals of the Royal College of Surgeons of England. 2020; 102(5):32332. [DOI:10.1308/rcsann.2020.0097] [PMID]

[26] Delaplain PT, Phillips JL, Lundeberg M, Nahmias J, Kuza $\mathrm{CM}$, Sheehan BM, et al. No reduction in surgical site infection obtained with post-operative antibiotics in facial fractures, regardless of duration or anatomic location: A systematic review and meta-analysis. Surgical Infections. 2020; 21(2):11221. [DOI:10.1089/sur.2019.149] [PMID]

[27] Feng F, Tuchman S, Denninger JW, Fricchione GL, Yeung A. Qigong for the prevention, treatment, and rehabilitation of COVID-19 infection in older adults. The American Journal of Geriatric Psychiatry. 2020; 28(8):812-9. [DOI:10.1016/j. jagp.2020.05.012] [PMID] [PMCID]

[28] Buja A, De Polo A, De Battisti E, Sperotto M, Baldovin T, Cocchio $\mathrm{S}$, et al. The importance of sex as a risk factor for hospital readmissions due to pulmonary diseases. BMC Public Health. 2020; 20:53. [DOI:10.1186/s12889-019-8138-6] [PMID] [PMCID]
[29] Flemming S, Hankir M, Ernestus RI, Seyfried F, Germer $\mathrm{CT}$, Meybohm P, et al. Surgery in times of COVID-19-recommendations for hospital and patient management. Langenbeck's Archives of Surgery. 2020; 405(3):359-64. [DOI:10.1007/ s00423-020-01888-x] [PMID] [PMCID]

[30] Freckelton I. COVID-19, negligence and occupational health and safety: Ethical and legal issues for hospitals and health centres. Journal of Law and Medicine. 2020; 27(3):590-600. [PMID]

[31] Konda SR, Dankert JF, Merkow D, Lin CC, Kaplan DJ, Haskel JD, et al. COVID-19 response in the global epicenter: Converting a New York city level 1 orthopedic trauma service into a hybrid orthopedic and medicine COVID-19 management team. Journal of Orthopaedic Trauma. 2020; 34(8):411-7. [DOI:10.1097/BOT.0000000000001792] [PMID] [PMCID]

[32] Al-Benna S. Availability of COVID-19 information from national and international aesthetic surgery society websites. Aesthetic Plastic Surgery. 2020; 44(3):1043-6. [DOI:10.1007/ s00266-020-01751-w]

[33] Wu F, Hu M, Cao M, Ou M, Li Q, Liu Z. Giant mesenteric mixed hemangioma misdiagnosed as ovarian cyst: A case report and a literature review. Annals of Vascular Surgery. 2020; 67:567.e1-4. [DOI:10.1016/j.avsg.2020.03.004] [PMID]

[34] Zingaretti N, Contessi Negrini F, Tel A, Tresoldi MM, Bresadola V, Parodi PC. The impact of COVID-19 on plastic surgery residency training. Aesthetic Plastic Surgery. 2020; 44(4):1381-5. [DOI:10.1007/s00266-020-01789-w] [PMID] [PMCID] 
This Page Intentionally Left Blank 